\title{
Evaluation of the Functional Properties of Promising Dioscorea trifida L. Waxy Starches for Food Innovation
}

\author{
Elevina Pérez, ${ }^{1}$ Olivier Gibert, ${ }^{2}$ Agnès Rolland-Sabaté, ${ }^{3}$ Xiomara Segovia, ${ }^{1}$ \\ Teresa Sánchez, ${ }^{4}$ Max Reynes, ${ }^{2}$ and Dominique Dufour ${ }^{2,4,5}$ \\ ${ }^{1}$ Instituto de Ciencia y Tecnología de Alimentos (ICTA), Facultad de Ciencias, Universidad Central de Venezuela, \\ Colinas de Bello Monte, Caracas 1041-A, Venezuela \\ ${ }^{2}$ CIRAD, UMR Qualisud, TA B-95/15, 73 rue JF Breton, 34398 Montpellier Cedex 5, France \\ ${ }^{3}$ UR1268 Biopolymères Interactions Assemblages, INRA, F-44300 Nantes, France \\ ${ }^{4}$ CIAT, A.A 6713, Recta Cali-Palmira, Cali, Colombia \\ ${ }^{5}$ CIRAD, UMR Qualisud, Cali, Colombia
}

Correspondence should be addressed to Dominique Dufour, d.dufour@cgiar.org

Received 30 June 2011; Revised 25 August 2011; Accepted 25 August 2011

Academic Editor: R. J. Linhardt

Copyright () 2011 Elevina Pérez et al. This is an open access article distributed under the Creative Commons Attribution License, which permits unrestricted use, distribution, and reproduction in any medium, provided the original work is properly cited.

\begin{abstract}
Few natural waxy starches are offered to the industry demand. Therefore, the morphological, physical, and chemical characteristics of "Mapuey" waxy starch were assessed. Amylose contents of starches isolated from Dioscorea trifida L. ("Mapuey") landraces cultivated in the Amazons of Venezuela were lower $(<8.1 \%)$ than commercial Mapuey starch $(>8.7 \%)$. DSC onset gelatinization temperatures varied from 71.1 to $73.2^{\circ} \mathrm{C}$. All starches exhibited B-type patterns, with degrees of crystallinity varying from $28 \%$ to $33 \%$. The highest crystallinity was found for the starches exhibiting the highest amylose content. At $90^{\circ} \mathrm{C}$, solubility and swelling power varied from 2.3 to $4.3 \%$ and 20.9 to $32.8 \%$, respectively. Gel clarity was variable from 20.8 to $62.1 \%$. A $5 \%$ starch suspension induced a high RVA peak viscosity between 1667 and $2037 \mathrm{cP}$. This natural waxy yam resource is a promising ingredient for food industry.
\end{abstract}

\section{Introduction}

Cush-cush yam locally called "Mapuey" in Venezuela (Dioscorea trifida L.) is the most important edible yam from the Amerindian family of the Dioscorea genus $[1,2]$. In addition to the commercial $D$. trifida L. crops, which are sold and consumed within boiled or mashed dishes, or in soup by the local population of the Venezuelan eastern region, there are several clones with colored skin, cultivated mostly in the small "chagras" gardens in the Amazon region $[3,4]$. Mapuey is an important source of carbohydrates for the tropical region of the world (starch represents about 38\% of the tuber on wet weight basis). Starch has been reported having amylose content in the $34.7-43.3 \%$ range for white and purple varieties [5]. Its physicochemical and functional properties have been reviewed on yam crops, such as D. alata, D. cayenensis, D. esculenta, D. rotundata, and D. dumetorum, with an average amylose content reported being above $7 \%$ [6]. Amylose contents are reported in the $27.5-36.2 \%$ range for Dioscorea alata grown in South America [7]. Three $D$. trifida L. landraces with low amylose contents grown in the Amazon region of Venezuela were discovered [8]. Pérez and coworkers [8] reported that the amperometric amylose and DSC amylose determinations varied from 2.2 to $5.9 \%$, and 1.4 to $3.5 \%$, respectively, for the Amazonian landraces in comparison with those from a commercial $D$. trifida $\mathrm{L}$. starch, reported from $8.7 \%$ by DSC to $9.5 \%$ by amperometry. From an industrial point of view, starches with low amylose content are well appreciated by the food processors due to their functional properties. Thereby, the objective of this work was to further characterize and promote the functional properties of waxy starches isolated from the three Dioscorea trifida landraces identified while exhibiting low-amylose starch. 


\section{Materials and Methods}

\subsection{Materials}

2.1.1. Starch Isolation. Starches extracted from three Dioscorea trifida crops of approximately $6 \mathrm{~kg}$ each (2 or 3 tubers) being collected in years 2005 and 2009 and $5 \mathrm{~kg}$ of one commercial crop bought from Güiria (Sucre State) local market in 2009 were isolated as previously described [8]. Tubers cleaned and rinsed with tap water were sliced and pounded for $2 \mathrm{~min}$ in a waring blender with twice their volume of distilled water. After passing five times the homogenate through a 200-mesh sieve, the slurry was centrifuged $(15 \mathrm{~min}$ at $1500 \mathrm{rpm})$. The sediment without mucilage being washed by suspension in distilled water was then oven-dried at $45^{\circ} \mathrm{C}$. The starches being blended and sieved (60 mesh sieve) were designed as "Amazonian white (AW)," "Amazonian light purple (ALP)," "Amazonian dark purple (ADP)," and "commercial white (CW)" and were hermetically stored until analysis.

2.1.2. Starch Yield. The starch isolation was performed quantitatively, using $100 \mathrm{~g}$ of edible tuber pulp and weighing of the isolated starch. The yield in percentage $(\mathrm{w} / \mathrm{w})$ was calculated as the ratio of the dry starch weight to the edible portion weight. All data were obtained in triplicate. Except for the commercial white (2009), mean values from the two years' crops (2005 and 2009) were calculated.

\subsection{Methods}

2.2.1. Tubers and Starch Granular Morphologies. The methodologies used to obtain the results described below were extensively reported [8]. Pictures of the three Dioscorea trifida tubers harvested in 2009 were taken for comparison of their external appearance. In addition, granular shape and Maltese crosses were also observed by optical microscopy using a polarized light filter. Photographs were also taken using a JEOL JSM-6490 scanning electron microscope (50 nm gold coating on a Denton vacuum Desk IV Ion Sputter at $20 \mathrm{kV}$ ) for granular shape, size, and distribution.

2.2.2. Purity. Starches were analyzed for moisture, crude protein $(\mathrm{N} \times 6.25)$, and ash contents using the methods AACC 44-15A, AACC 46-13, and AACC 08-01 [9], and the fatty material was analysed using the Schoch procedure [10]. The percent of purity of starch was then calculated from the difference between 100 and the percentage of moisture, crude protein, fatty material, and ash content.

\subsubsection{Physicochemical Properties of Starch}

Onset Temperature, Gelatinization Enthalpy Change, and Amylose Determination by DSC. Onset temperature, gelatinization enthalpy change $(\Delta \mathrm{H})$, and DSC amylose determination were carried out in duplicate according to Amani et al. [11] on a Perkin-Elmer DSC 7 device (Perkin-Elmer, Norwalk, Conn, USA). Amylose content was measured from the energy of amylose/lysophospholipid complex formation using DSC from the cooling stage of the thermogram previously used for the gelatinization onset temperature determination. As a slight modification, $40 \mu \mathrm{L}$ of lysophospholipid $2 \%$ (w/v in water) was used with 10 to $11 \mathrm{mg}$ of starch to form the amylose/lysophospholipid complex.

Colorimetric and Amperometric Amylose Determination. Colorimetric amylose determination was carried out following the standard ISO6647 procedure as already described [8]. Amperometric method [12] was applied to the starch samples after defatting and solubilisation in $1 \mathrm{~N} \mathrm{KOH}$ for 3 days at $4^{\circ} \mathrm{C}$ under stirring using amylose as a reference for iodine-binding capacity, as previously described [8]. The wavelength at maximum absorption $\left(\lambda_{\max }\right)$ of the iodine complexes with starches was determined for the same solutions as described by Pérez et al. [8]. Spectra were recorded between 450 and $750 \mathrm{~nm}$. The $\lambda_{\max }$ was determined by the first derivative.

Gel Clarity. The methodology reported by Ceballos et al. [13] was used. A 1\% dry basis aqueous dispersion of starch was boiled at $96.5^{\circ} \mathrm{C}$ with thorough shaking every $5 \mathrm{~min}$ for $30 \mathrm{~min}$. After the starch had cooled to room temperature, transmittance was measured at $650 \mathrm{~nm}$.

\subsubsection{Functional Properties of Starch}

Swelling Power, Solubility, and Dispersed, Volume Fraction. Swelling power, solubility, and dispersed volume fraction measurements were carried out according to Ceballos et al. [13] and modified by Pérez et al. [8]. The 2.5\% db (w/w) starch suspension was prepared in a Rapid Visco-Analyser (RVA model RVA-4 Series, Newport Scientific, Australia) and heated and maintained at $75^{\circ} \mathrm{C}$ or $90^{\circ} \mathrm{C}$ prior to being centrifuged at $6000 \mathrm{~g}$ for $10 \mathrm{~min}$ at $25^{\circ} \mathrm{C}$. The sediment and supernatant were weighed and dried. The solubility, swelling power, and the volume fraction of the dispersed phase were then calculated according to Pérez et al. [8]. All data were obtained in duplicate, and mean values from the two years' crops (2005 and 2009) were calculated.

Pasting Properties. Starch pasting properties were obtained with the RVA using a 5\% starch suspension and the temperature profile earlier described [8]. After a holding phase at $50^{\circ} \mathrm{C}$ for $1 \mathrm{~min}$, the suspension was heated to $90^{\circ} \mathrm{C}$ at $6^{\circ} \mathrm{C} \mathrm{min} \mathrm{m}^{-1}$, held $5 \mathrm{~min}$ at $90^{\circ} \mathrm{C}$, and then cooled to $50^{\circ} \mathrm{C}$ at $6^{\circ} \mathrm{C} \mathrm{min}^{-1}$. With the pasting temperature, the peak viscosity, the hot paste viscosity and cool paste viscosity, the breakdown, setback, and consistency parameters were estimated [14]. All data were obtained in duplicate and mean values from the two years' crops (2005 and 2009) were calculated.

$X$-Ray Diffractometry. After the adjustment of the water content at $90 \%$ relative humidity for 20 days under partial vacuum using a saturated barium chloride salt solution, $\mathrm{X}$-ray diffraction was performed on native starches. The 


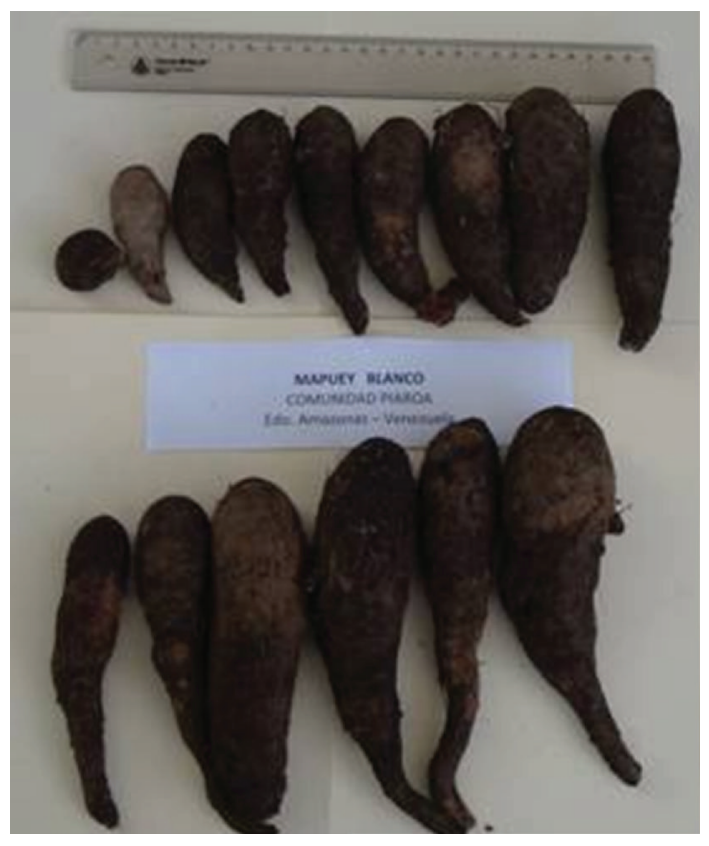

(a)

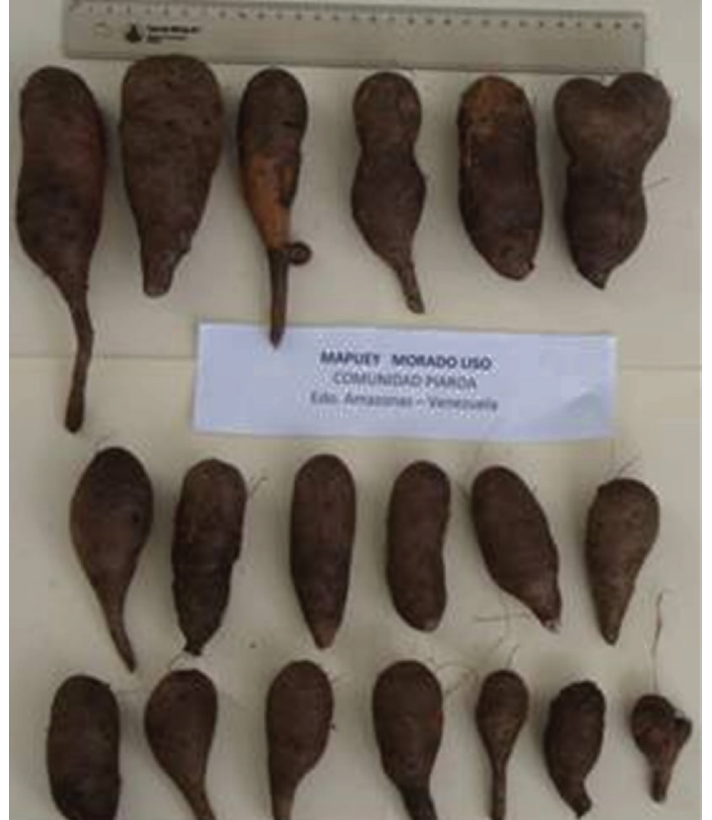

(b)

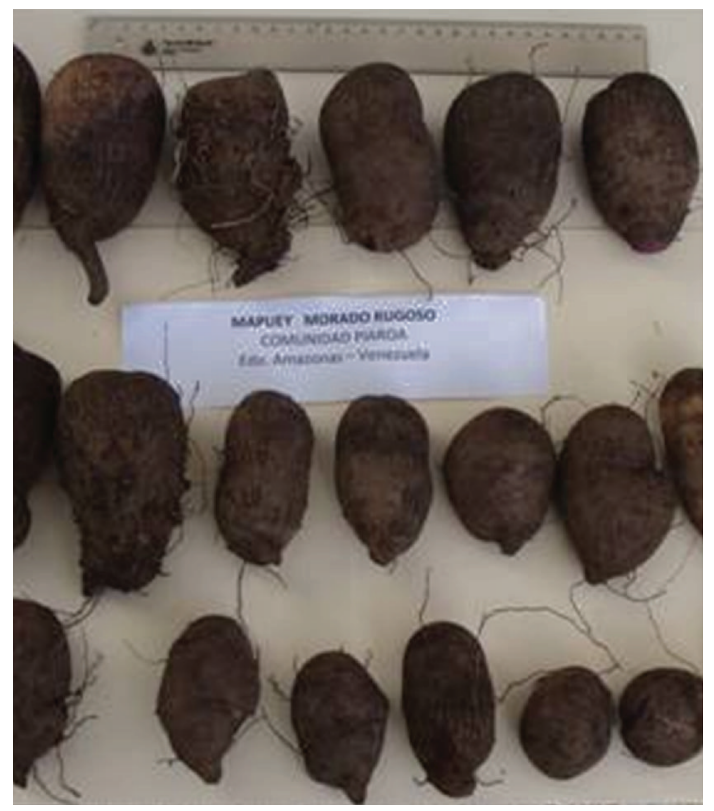

(c)

Figure 1: External appearances of the three landraces of Dioscorea trifida L., harvested in 2005 and 2009: (a) Amazonian white (AW); (b) Amazonian light purple (ALP), and (c) Amazonia dark purple (ADP).

methodology used is exhaustively described by Pérez et al. [8].

\section{Results and Discussion}

3.1. Tubers and Starch Granular Morphologies. There is a consensus on some physical differences that can be observed among botanical resources. One can also expect some starch functional differences to be origin specific. The three Amazonian landraces exhibited some noticeable morphological differences (Figure 1). Dark purple tubers seemed to have rougher superficial aspect and smaller round size than those of the light purple and the white tubers. However, a similar extended shape, obtuse and wider toward one end and taillike at the other, was observed among the three Amazonian crops. Both scanning electron micrograph and polarized optical light micrograph of the four native Dioscorea trifida starches isolated from 2005 and 2009 harvests showed an eccentric hilum and an irregular shape of the granules, with oval or shell-shaped large structures (Figure 2). The SEM 


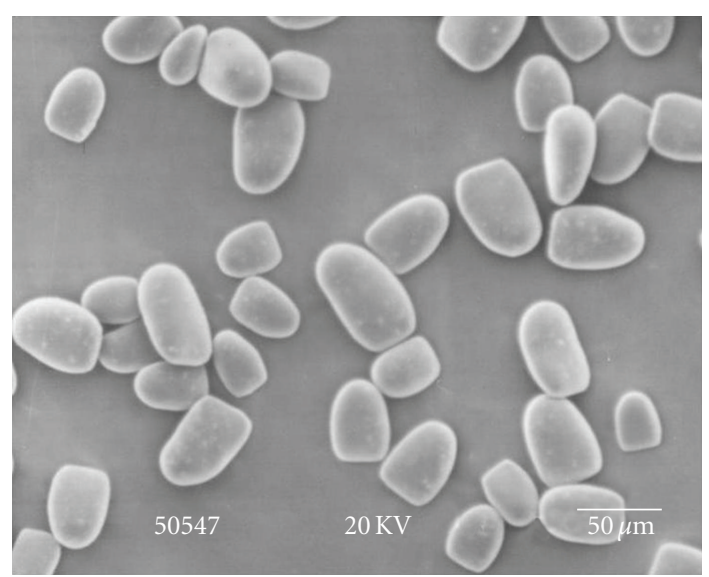

(a)

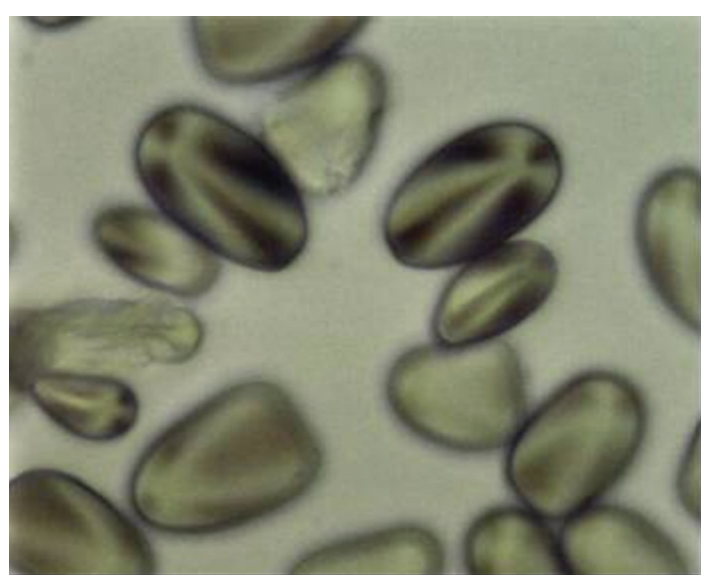

(b)

FIGURE 2: SEM (300x) (a) polarized optical light microscopy (100x) (b) micrographs of the AW starch isolated from Dioscorea trifida L harvested in 2005 and 2009.

TABLE 1: Amylose content percentages of the starches isolated from the four yam varieties and at two harvesting years and estimated by differential scanning calorimetry, amperometry, and colorimetry.

\begin{tabular}{lcccc}
\hline & Commercial & & Amazonian \\
Parameters & White $(\mathrm{CW})$ & White (AW) & Light purple (ALP) & Dark purple (ADP) \\
\hline \% purity (w/w) & 99.9 & 99.7 & 99.7 & $17.5 \pm 0.1$ \\
\% yield (w/w) & $22.5 \pm 0.1$ & $19.0 \pm 0.0$ & $2.0-3.5$ & $1.5 \pm 0.0$ \\
DSC amylose (\%) & 8.6 & $1.3-2.7$ & $1.4-5.5$ & $3.0-8.0$ \\
Colorimetric amylose (\%) & 11.9 & $1.8-2.0$ & $3.4-3.7$ & $2.2-5.9$ \\
Amperometric amylose (\%) & 9.5 & $2.2-2.4$ & $550-558$ & $547-554$ \\
$\lambda_{\max }(\mathrm{nm})$ & 593 & $550-565$ & & \\
\hline
\end{tabular}

micrography (a) showed granular sizes from 25 to $70 \mu \mathrm{m}$, with granular smooth shapes. The complementary micrography (b) made on a polarized optical light microscopy showed typical Maltese cross, which indicated the native stage of the starch molecular order.

3.2. Physicochemical Properties. The starch gelatinization profile measured by DSC showed a relatively high onset temperature for the four landraces, in the $71.1-73.2^{\circ} \mathrm{C}$ range, as illustrated on one of the two thermograms made of the landraces (Figure 3(a)). Onset temperatures were thereby in the range of 69.0 to $78.8 \%$, reported by Amani et al. [11]. The commercial white cultivar exhibited and intermediate onset temperature in comparison with the Amazonian landraces. The gelatinization enthalpy variation $(\Delta \mathrm{H})$ was in the $23.5-25.0 \mathrm{Jg}^{-1}$ range and represents the highest enthalpy reported in the literature for Dioscorea species. These high gelatinization variations may suggest a high degree of intermolecular associations among the amylopectin branches and/or between the amylose and the amylopectin branches. Thereby, more energy may be required for the full gelatinization of theses starches in comparison with conventional starch.

As illustrated in Figure 3(b), an exothermic peak was observed during the cooling stage, corresponding to the formation of the amylose/lysophospholid complexes of the different cultivars. If the Amazonian landraces exhibited a low peak with a limited DSC amylose variability (1.4 to 3.6\% of amylose estimated (Table 1), close to the detection limit), the starch isolated from commercial "Mapuey" would exhibit a major peak for the amylose-lipid complex. The amylose content of the commercial tuber was then estimated at about 8.7\% (Table 1).

The purity of the four Dioscorea trifida starches was high (varying from 99.70 to $99.90 \%$ for the ADP and the CW, resp.), and was corroborated by the photomicrography (Figure 2). As shown in Table 1, the highest starch yield was obtained for the commercial white tuber with $22.5 \%$, whereas the other three yields of the starches were fluctuating from $16.1 \%$ (ADP) to $19.0 \%(\mathrm{AW})$.

Starch amylose contents determined by amperometric method IBC were in the $2.2-5.9 \%$ range for defatted Amazonian samples, whereas the commercial sample exhibited about $9.5 \%$. The colorimetric method gave a similar trend with estimated amylose content slightly higher for the dark purple genotype, with $8.1 \%$ versus $5.9 \%$ by amperometry. This is a novel report on waxy Dioscorea sp., since the amylose contents of starches from different cultivars of Dioscorea are usually reported to be higher than 7.0\% [7].

Corresponding $\lambda_{\max }$ mean values ranged between 547 to $565 \mathrm{~nm}$ for the Amazonian landraces whereas CW exhibited a $\lambda_{\max }$ of $593 \mathrm{~nm}$. $\lambda_{\max }$ values were in accordance with those 

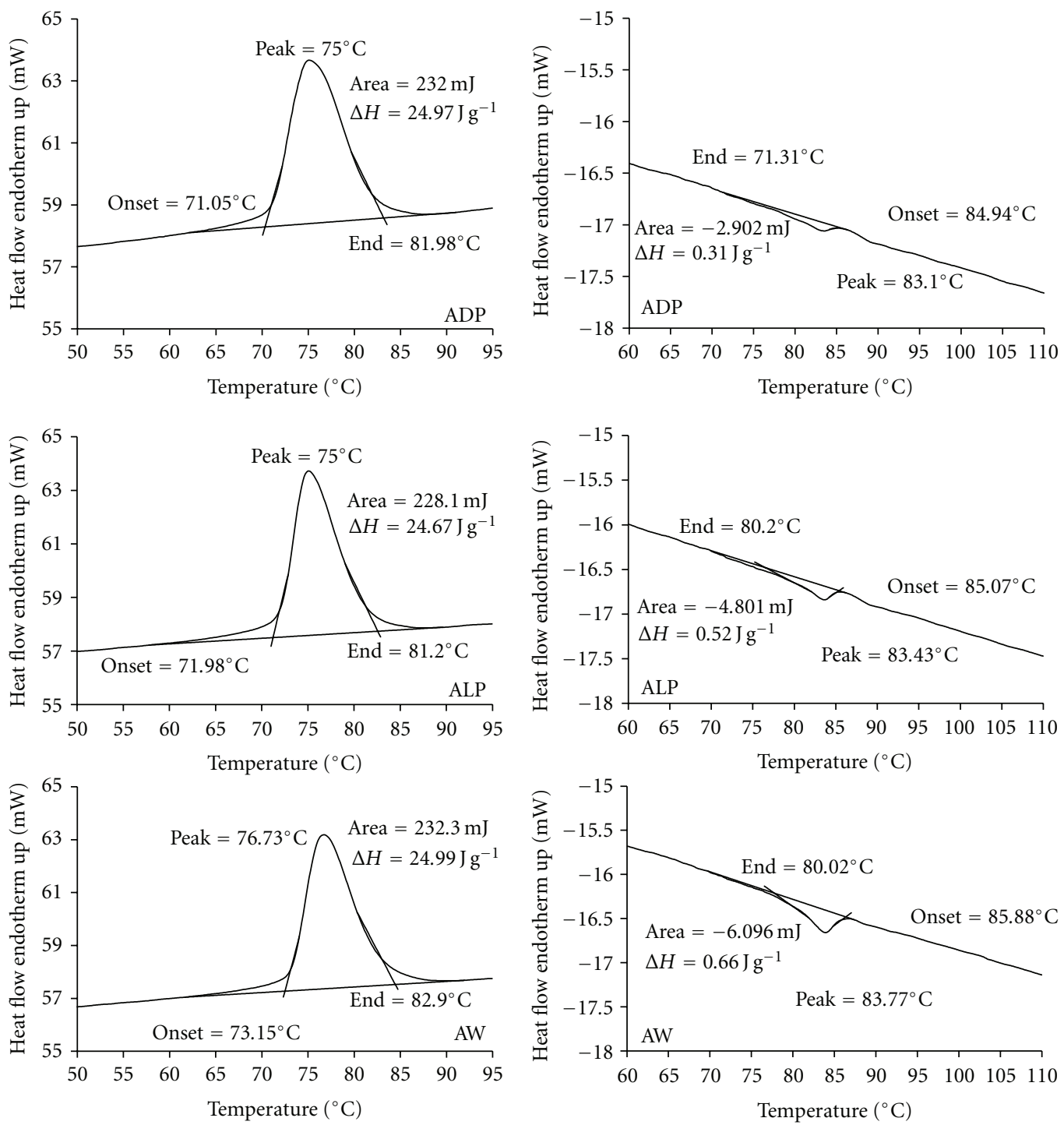

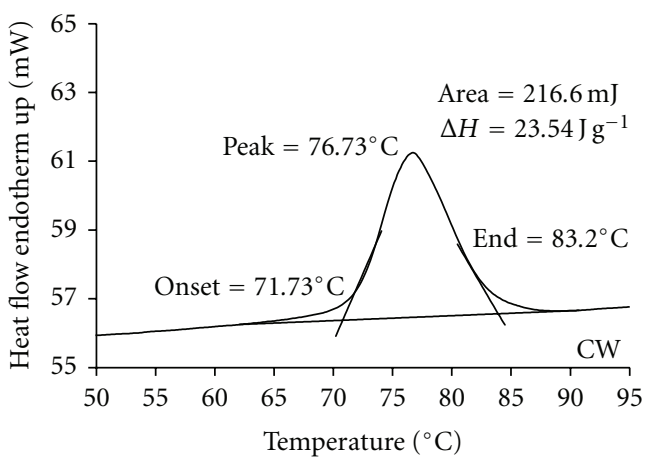

(a)

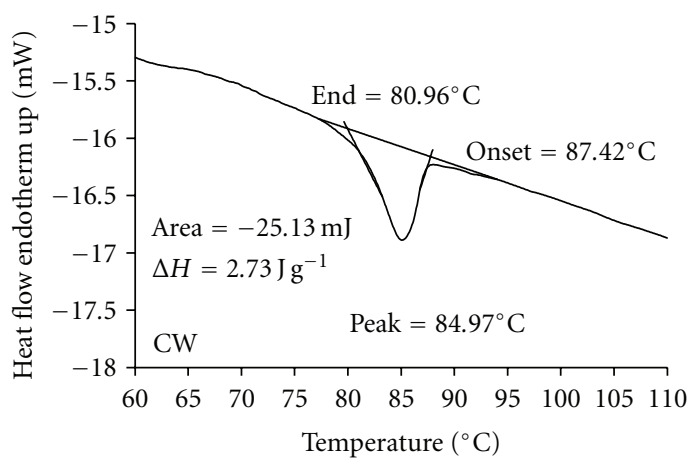

(b)

Figure 3: (a) Differential scanning calorimeter results from ADP, ALP, AW, and CW (one of the two analyses made) in the heating phase. (b) Differential scanning calorimeter results from ADP, ALP, AW, and CW (one of the two analyses made) in the cooling phase.

reported by Tetchi et al. [15] and Sánchez et al. [16] and thus confirmed that ADP, ALP, and AW starches contained the lowest amount of amylose or chains with shorter length.

Some considerable variation in gel clarity of the Dioscorea trifida starches extracted can be also highlighted (Table 2).
Amazonian cultivars exhibited gel clarity in the $24.3-79.2 \%$ range, whereas the commercial cultivar exhibited a "usual" gel clarity percentage around 22\%. Amani et al. [11] reported some clarity for some cultivars of Dioscorea starch gels from Côte d'Ivoire between $8.9 \%$ and $62.3 \%$. The amylose-free 
TABLE 2: Granular structure and some functional properties of waxy Dioscorea trifida starches.

\begin{tabular}{|c|c|c|c|c|c|}
\hline \multirow[b]{2}{*}{ Parameters } & & \multirow{2}{*}{$\begin{array}{l}\text { Commercial } \\
\text { White (CW) }\end{array}$} & \multicolumn{3}{|c|}{ Amazonian } \\
\hline & & & White (AW) & Light purple (ALP) & Purple dark (ADP) \\
\hline Gel clarity $(\%)$ & & $20.8-23.5$ & $50.8-55.6$ & $48.3-79.2$ & $24.3-62.1$ \\
\hline \multirow{2}{*}{ Solubility (\%) } & $75^{\circ} \mathrm{C}$ & $3.5 \pm 0.3$ & $2.6 \pm 0.2$ & $4.1 \pm 0.3$ & $2.5 \pm 0.5$ \\
\hline & $90^{\circ} \mathrm{C}$ & $4.3 \pm 0.2$ & $2.3 \pm 0.2$ & $3.6 \pm 1.1$ & $3.1 \pm 0.8$ \\
\hline \multirow{2}{*}{ Swelling power } & $75^{\circ} \mathrm{C}$ & $13.6 \pm 1.0$ & $21.0 \pm 2.5$ & $23.3 \pm 4.5$ & $22.7 \pm 0.7$ \\
\hline & $90^{\circ} \mathrm{C}$ & $20.9 \pm 0.7$ & $26.0 \pm 7.5$ & $32.8 \pm 6.6$ & $26.8 \pm 7.6$ \\
\hline \multirow{2}{*}{ Dispersed phase $(\Phi)$} & $75^{\circ} \mathrm{C}$ & $0.4 \pm 0.0$ & $0.6 \pm 0.1$ & $0.7 \pm 0.1$ & $0.6 \pm 0.0$ \\
\hline & $90^{\circ} \mathrm{C}$ & $0.6 \pm 0.0$ & $0.7 \pm 0.1$ & $0.8 \pm 0.1$ & $0.7 \pm 0.1$ \\
\hline Granule size distribution $(\mu \mathrm{m})$ & & 33.5 & 27.2 & 33.5 & 34.5 \\
\hline Crystallinity (\%) & & 33 & 28 & 28 & 24 \\
\hline Moisture (\%) & & 22.9 & $22.8 \pm 0.5$ & $22.6 \pm 0.1$ & $22.4 \pm 1.3$ \\
\hline
\end{tabular}

Except for the "commercial white," the means values obtained for two years' crops 2005 and 2009 were reported.

The experimental uncertainties were about $5 \%$ for amylose, crystallinity and granule sizes contents and less than $1 \%$ for $\lambda_{\max }$ values.

The granule size corresponded to the average granule diameter.

Results are the means three determinations.

TABLE 3: RVA gelatinization profile of waxy Dioscorea trifida starches.

\begin{tabular}{lcccc}
\hline & Commercial & \multicolumn{3}{c}{ Amazonians } \\
Parameters & White $(\mathrm{CW})$ & White $($ AW $)$ & Light purple ((ALP) & Dark purple (ADP) \\
\hline Peak viscosity $(\mathrm{cP})$ & $*$ & 1667 & 2037 & 1848 \\
Pasting temperature $\left({ }^{\circ} \mathrm{C}\right)$ & 78.08 & 76.90 & 76.20 & 78.50 \\
Breakdown $(\mathrm{cP})$ & $*$ & 375 & 695 & 683 \\
Setback $(\mathrm{cP})$ & $*$ & -397 & -764 & -694 \\
Consistency $(\mathrm{cP})$ & -1002 & 29 & 69 & -330 \\
\hline
\end{tabular}

Except for CW, results are the means of two determinations and two harvesting years (2005 and 2009).

* Results not computed due to the absence of peak.

Dioscorea trifida clone exhibited the clearest yam gel, with an intermediate clarity between cassava (50\%), waxy cassava $(61 \%)$, waxy potato $(88 \%)$, and waxy potato starch $(92 \%)$, according to Sánchez et al. [16].

3.3. Functional Properties. These waxy starches exhibited substantially lower solubility at $90^{\circ} \mathrm{C}$ when compared with the same nonwaxy Dioscorea species (Table 2), but grown at different locations [5]. Solubility was relatively lower, but a higher swelling power was obtained at $90^{\circ} \mathrm{C}$ when compared with those reported above, in addition to those reported by some other authors [17]. The volume fraction of dispersed phase was slightly higher in ALP (0.8) which presents the highest swelling power, when compared with the starches from the other two waxy landraces (0.6 to 0.7$)$.

With a monomodal distribution, granule sizes were in the $27.2-34.5 \mu \mathrm{m}$ range (Table 2 ), and the granule size distributions were of the same order of magnitude of that obtained previously for yam starches [11]. All starches earlier investigated exhibited B-type crystallinity $[8,18]$. Pérez et al. [8] reported earlier the absence of A-type crystals for the yam landraces with low amylose contents.

In comparison with potato, maize, rice, and cassava starches [16], the Dioscorea trifida L., "Mapuey," starches exhibited a lower viscosity than normal potato and waxy potato at 5\% suspension with 1667-2037 versus 2400$2500 \mathrm{cP}$, but significantly higher viscosities than those of maize and waxy maize, rice, and cassava starches. Similarly to potato starch, Dioscorea starches exhibited high viscosities but with higher pasting temperatures (Table 3). If Sánchez et al. [16] also reported the lowest pasting temperatures for normal starches in roots and tubers, the high pasting temperature of Dioscorea trifida tubers seems a technological valuable specificity of yam crop. In addition to the hot paste viscosity, high breakdown can be observed for the Amazonian landraces. Rached et al. [5] earlier suggested a fragile granule structure of the white "Mapuey" due to the high breakdown. The authors also suggested a low tendency of the genotype to retrograde due to the limited setback estimated. White Amazonian waxy genotype also exhibited here a limited setback, in comparison to genotypes of the light purple and dark purple landraces, whereas significantly lower consistency was here measured for the Amazonian landraces, in comparison to that of the commercial white tuber.

\section{Conclusion}

Starches were white and waxy with quite low amylose being estimated and exhibited homogeneous rheological behavior. The patterns of solubility and swelling power were different from those of nonwaxy starches. The most important result consisted in revealing special and unreported physical and functional properties, concerning the amylose contents, gel 
clarities, paste viscosities and crystallinity of starches isolated from the Venezuelan Dioscorea trifida landraces. After the discovery of a natural waxy mutation in roots [13], the waxy yam is therefore the first natural waxy tuber starch discovered to be promoted.

\section{Acknowledgments}

The authors would like to thank the Post-graduate Cooperation Programs (PCP) between French Ministry of Foreign and European Affairs (France) and FONACIT (Venezuela) for the financial support for the study between the Instituto de Ciencia y Tecnología de Alimentos de la Facultad de Ciencias-Universidad Central de Venezuela (Caracas, Venezuela) and CIRAD (Montpellier, France). The authors would like also to thank DESI-CIRAD for their financial support in receiving Latin American scientists in France.

\section{References}

[1] D.G. Coursey, "The origins and domestication of yams in Africa," in Origin of African Plant Domestication Mouton, J. R. Harlan, J. M. J. De Wet, A. B. L. Stemler Mouton et al., Eds., pp. 383-408, Hague, Amsterdam, The Netherlands, 1976.

[2] G. Arnau, K. Abraham, M. N. Sheela, H. Chaïr, A. Sartie, and R. Asiedu, "Root and tuber crops: yams," in Handbook of Plant Breeding, J. E. Bradshaw, Ed., vol. 7, pp. 127-148, Springer, New York, NY, USA, 2010.

[3] G. A. Velez, "The chagra: collective patrimony of the indigenous amazonian communities," Beyond Law, vol. 6, pp. 121$142,1998$.

[4] F. W. Martin and L. Degras, "Dioscorea trifida," in Tropical Yams and Their Potential, vol. 522, part 5 of Handbook, pp. 1-3, U.S. Department of Agriculture, Washington, DC, USA, 1978.

[5] L. B. Rached, C. A. De Vizcarrondo, A. M. Rincón, and F. Padilla, "Evaluation of the flour and starch from white and purple varieties of mapuey (Dioscorea trifida)," Archivos Latinoamericanos de Nutrición, vol. 56, no. 4, pp. 375-383, 2006.

[6] R. Hoover, "Composition, molecular structure, and physicochemical properties of tuber and root starches: a review," Carbohydrate Polymers, vol. 45, no. 3, pp. 253-267, 2001.

[7] R. A. Freitas, R. C. Paula, J. P. A. Feitosa, S. Rocha, and M.R. Sierakowski, "Amylose contents, rheological properties and gelatinization kinetics of yam (Dioscorea alata) and cassava (Manihot utilissima) starches," Carbohydrate Polymers, vol. 55, no. 1, pp. 3-8, 2003.

[8] E. Pérez, O. Gibert, A. Rolland-Sabaté et al., "Physicochemical, functional, and macromolecular properties of waxy yam starches discovered from "mapuey" (Dioscorea trifida) genotypes in the venezuelan amazon," Journal of Agricultural and Food Chemistry, vol. 59, no. 1, pp. 263-273, 2011.

[9] AACC. American Association of Cereal Chemists, Laboratory Methods, St. Paul, Minneapolis, Minn, USA, 10th edition, 2003, Methods, no. 44-15A, 46-13, and 08-01.

[10] T. Schoch, "Fatty substances in starch," in Methods in Carbohydrates Chemistry, R. Whistler, Ed., vol. 4, Academic Press, New York, NY, USA, 1964.

[11] N'. G. G. Amani, D. Dufour, C. Mestres, A. Buléon, A. Kamenan, and P. Colonna, "Variability in starch physicochemical and functional properties of yam (Dioscorea sp) cultivated in
Ivory Coast," Journal of the Science of Food and Agriculture, vol. 85 , no. 5, p. 889, 2005.

[12] B. L. Larson, K. A. Gilles, and R. Jenness, "Amperometric method for determining the sorption of iodine by starch," Analytical Chemistry, vol. 25, no. 5, pp. 802-804, 1953.

[13] H. Ceballos, T. Sánchez, N. Morante et al., "Discovery of an amylose-free starch mutant in cassava (Manihot esculenta Crantz)," Journal of Agricultural and Food Chemistry, vol. 55, no. 18, pp. 7469-7476, 2007.

[14] D. Dufour, O. Gibert, A. Giraldo et al., "Differentiation between cooking bananas and dessert bananas. 2. thermal and functional characterization of cultivated colombian Musaceae (Musa sp.)," Journal of Agricultural and Food Chemistry, vol. 57, no. 17, pp. 7870-7876, 2009.

[15] F. A. Tetchi, A. Rolland-Sabaté, N'. G. G. Amani, and P. Colonna, "Molecular and physicochemical characterisation of starches from yam, cocoyam, cassava, sweet potato and ginger produced in the Ivory Coast," Journal of the Science of Food and Agriculture, vol. 87, no. 10, pp. 1906-1916, 2007.

[16] T. Sánchez, D. Dufour, I. X. Moreno, and H. Ceballos, "Comparison of pasting and gel stabilities of waxy and normal starches from potato, maize, and rice with those of a novel waxy cassava starch under thermal, chemical, and mechanical stress," Journal of Agricultural and Food Chemistry, vol. 58, no. 8, pp. 5093-5099, 2010.

[17] N. Akissoe, C. Mestres, S. Handschin, O. Gibert, J. Hounhouigan, and M. Nago, "Microstructure and physico-chemical bases of textural quality of yam products," LWT-Food Science and Technology, vol. 44, no. 1, pp. 321-329, 2011.

[18] S. Srichuwong, T. C. Sunarti, T. Mishima, N. Isono, and M. Hisamatsu, "Starches from different botanical sources I: contribution of amylopectin fine structure to thermal properties and enzyme digestibility," Carbohydrate Polymers, vol. 60 , no. 4, pp. 529-538, 2005. 


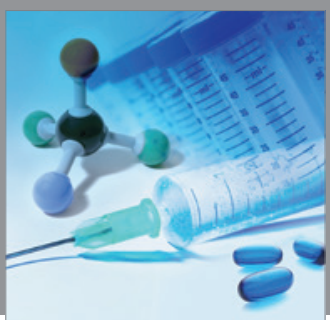

International Journal of

Medicinal Chemistry

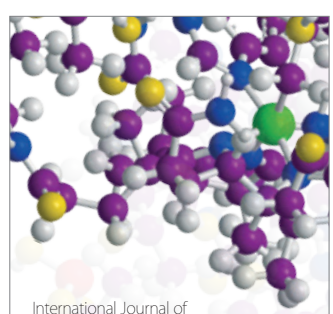

Carbohydrate Chemistry

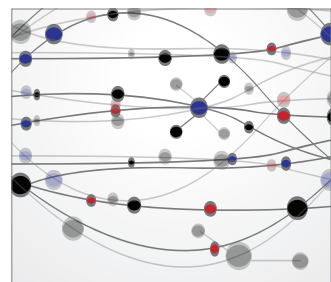

The Scientific World Journal
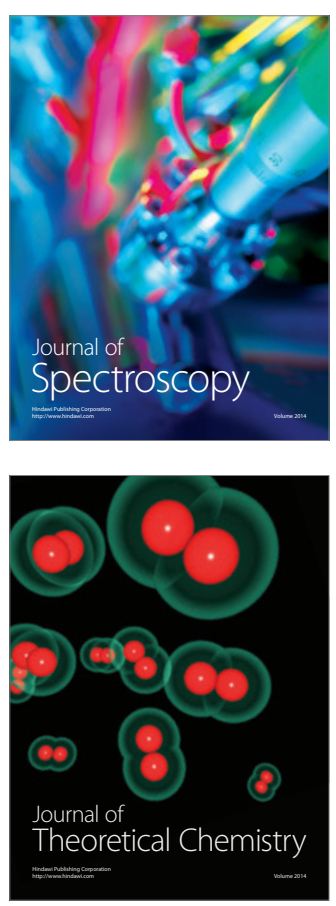
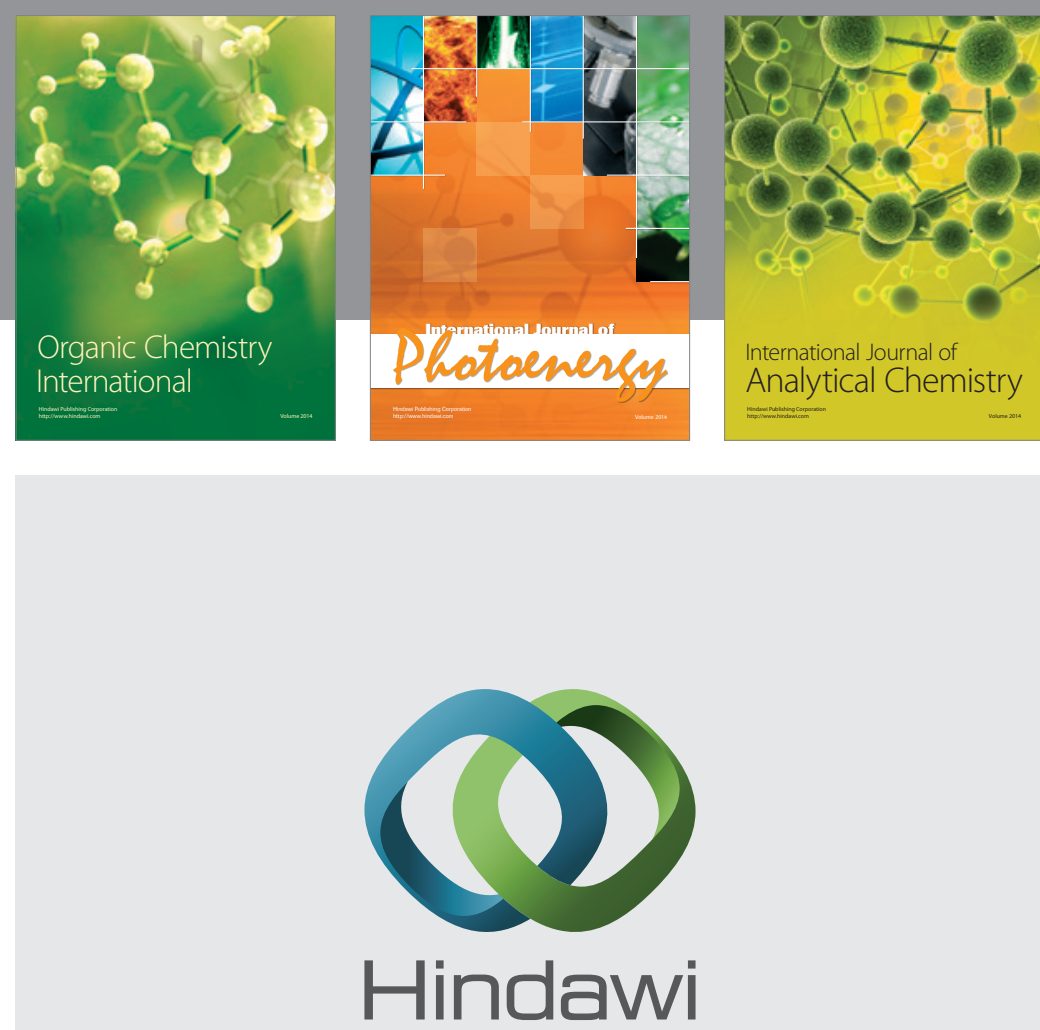

Submit your manuscripts at

http://www.hindawi.com
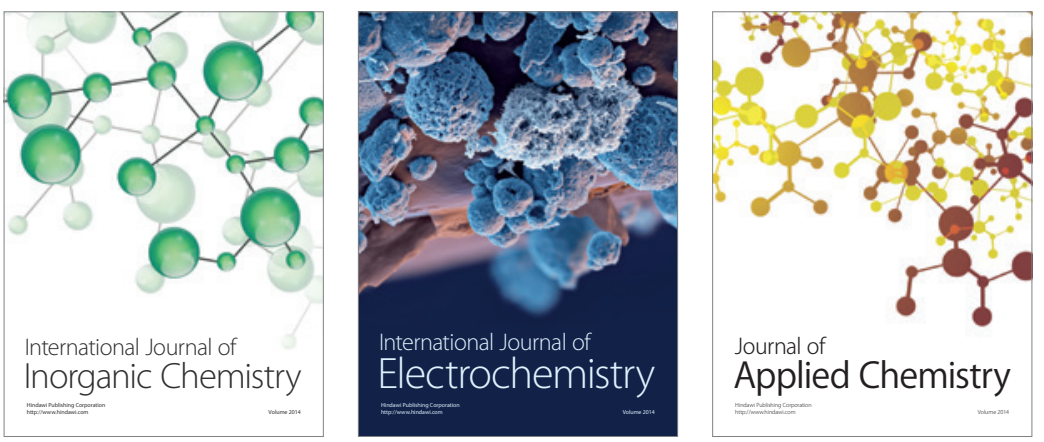

Journal of

Applied Chemistry
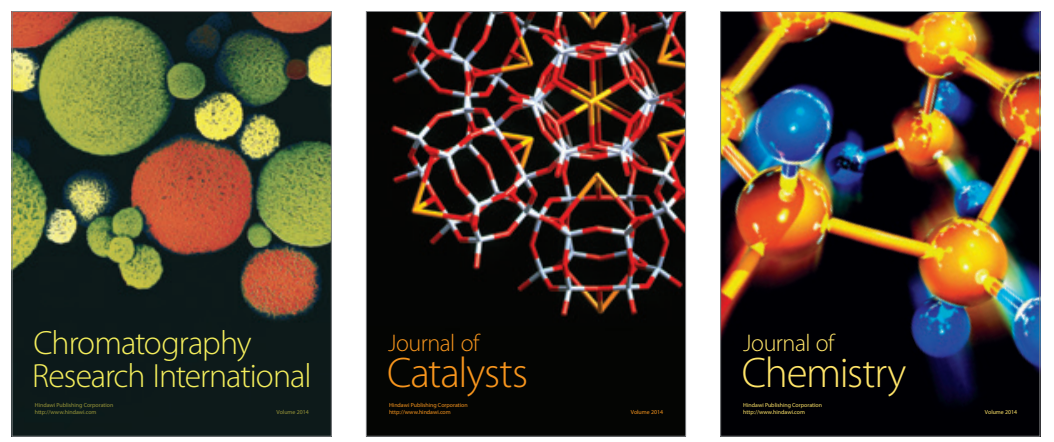
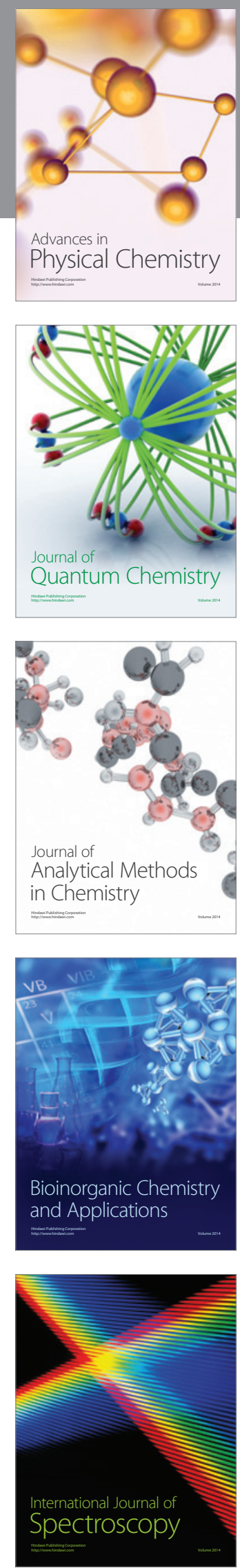